\title{
ATEB B
}

Dinî Araștırmalar Dergisi Journal for Religious Studies e-ISSN: 2757-5616

\section{Vahyin Şahidi, Kur'an'ın Müfessiri Hz. Aișe. Hatice Görmez. Ankara: 0TTO Yayınları, 2021.}

\author{
Değerlendiren/Review by \\ Bünyamin Erul \\ Prof. Dr., Ankara Üniversitesi, İlahiyat Fakültesi, Hadis Anabilim Dalı \\ Professor, Ankara University, Department of Hadith \\ Ankara, Turkey \\ berul@ankara.edu.tr \\ orcid.org/ 0000-0003-0630-4147 \\ https://ror.org/01wntqw50
}

\section{Makale Bilgisi / Article Information}

Makale Türü / Article Types: Kitap Değerlendirmesi / Book Review Geliș Tarihi / Date Received: 18 Kasım/November 2021

Kabul Tarihi / Date Accepted: 17 Aralı/December 2021

Yayın Tarihi / Date Published: 31 Aralı/December 2021

Yayın Sezonu / Pub Date Season: Aralık/December

Atıf / Cite as: Erul, Bünyamin. “Vahyin Şahidi, Kur’an'ın Müfessiri Hz. Aişe. Hatice Görmez. Ankara: OTTO Yayınları, 2021”. ATEBE 6 (Aralık 2021), 193-198. https://doi.org/10.51575/atebe.1025562

İntihal / Plagiarism: Bu makale, iTenticate yazılımınca taranmıştır. İntihal tespit edilmemiştir/This article has been scanned by iTenticate. No plagiarism detected.

Etik Beyan/Ethical Statement: Bu çalışmanın hazırlanma sürecinde bilimsel ve etik ilkelere uyulduğu ve yararlanılan tüm çalışmaların kaynakçada belirtildiği beyan olunur/It is declared that scientific and ethical principles have been followed while carrying out and writing this study and that all the sources used have been properly cited (Bünyamin Erul).

Yayıncı / Published by: Ankara Sosyal Bilimler Üniversitesi / Social Sciences University of Ankara. $\mathrm{Bu}$ makale Creative Commons Alıntı-GayriTicariTüretilemez 4.0 (CC BY-NC 4.0) Uluslararası Lisansı altında lisanslanmıștır. This article is an open access article distributed under the terms and conditions of the Creative Commons Attribution-NonCommercial-NoDerivatives 4.0 (CC BY-NC 4.0) International License. 
Vahyin Şahidi, Kur'an'ın Müfessiri Hz. Aişe. Hatice Görmez. Ankara: OTTO

Yayınları, 2021.

\title{
Öz
}

Yazıya konu edilen kitap, Hatice Görmez'in “Hz. Âișe'nin Tefsir Rivâyetleri” bașlıklı yüksek lisans tezinin geliştirilmiş halidir. Eserde Hz. Âișe'nin hayatı ve ilmî kişiliği, Kur'an'ı anlama ve yorumlama metodu, Kur'an tefsiri konusundaki rivayetleri, Kur'an ilimlerine dair rivayetleri, tefsirle ilișkili istidrakleri ve fetvaları, fezâil ve hasâisu'n-nebi rivayetleri, tefsir kaynaklarında farklı bağlamlarda değerlendirilen rivayetleri ve Hz. Âișe'ye isnad edilen zorlama ve uydurma tefsir rivayetleri gibi konular ele alınmıştır. Eserinde hem edebî hem ilmî bir üslup kullanan yazar, Hz. Âișe'nin yaşı ve İfk hadisesi gibi tartışmalı konulara da değinmiş ve bu konulardaki bakış açısını okuyucuya sunmuştur. Bu iddialar tartışılırken bazı rivayetlerin ve bazı tarihi bilgilerin göz ardı edilmesi eserin tenkit edilen yönlerindendir. Bunun yanı sıra eser, ilim geleneğimizi etkileyen önemli isimlerden biri olan Hz. Âişe'nin ilmî yönünü ve bilhassa tefsirciliğini pek çok rivayetle başarılı bir şekilde sunması bakımından övgüyü hak etmektedir.

Anahtar Kelimeler: Tefsir, Vahiy, Rivayet, Hz. Âişe, Tenkit.

\section{The Witness of The Waḥy, The Commentator of Qur'ān Hz. Aisha, Hatice Görmez.}

Ankara: Otto Publications, 2021.

\begin{abstract}
The subject of this article is Hatice Gormez's book which is improved version of the master's thesis titled "Aisha's Tafsīr Rivāyahs". In the work, 'Ā'isha bt. Abī Bakr's life and scientific personality, her method of understanding and interpreting the Qur'ān, her rivāyahs on 'ulūm al-Qur'ān, her rivāyahs on 'ulūm alQur'ān, her istidraqs and fatwās related to tafsir, the narrations of fezâil and hasaisu'n-nebi, her narratives evaluated in the different sources of tafsīr, and compelled and fabricated tafsīr rivāyahs attributed to ' $\overline{\mathrm{A}}$ 'isha were discussed. The author, who uses both a literary and scientific style in his work, touched upon controversial issues such as 'A' 'isha 's age and the amr al-ifk and presented her point of view on these issues. While discussing these claims, ignoring some rivāyahs and some historical information is one of the critics for the work. In addition, the work deserves praise for successfully presenting 'Â'isha's scientific side and especially her exegesis with many rivāyahs.
\end{abstract}

Keywords: Tafsīr, Waḥy, Rivāyah, 'Ā’isha bt. Abī Bakr, Criticism.

Haziran ayında okuyucuyla buluşan ve hayli emek mahsulü olan bu çalışma, yazarın 2016 yllında Ankara Üniversitesi, Sosyal Bilimler Enstitüsü'nde tamamladığı “ Hz. Âişe’nin Tefsir Rivâyetleri" başlıklı yüksek lisans tezinin geliștirilerek kitap kisvesine bürünmüş halidir. Çalışma, yazarın "Müminlerin Bilge Annesi Hz. Aişe'ye" başlıklı oldukça edebî ve bir o kadar da duygusal bir seslenişiyle bașlamaktadır. Önsöz'de pek çok konuda oldukça zengin bir rivayet malzemesi bırakan Hz. Âişe'den gelen haberlerin yarıya yakınının tefsir rivayetleri olarak değerlendirilmiş olması hasebiyle onun tefsirdeki yerine ve ehemmiyetine dikkat çekilmektedir. (s. 15) Giriş kısmında yazar, Hz. Âişe'nin Kur'an tefsiri konusundaki rivayetlerini bir bütün olarak ele almayı ve bir müfessir olarak onun tefsir ilmine katkılarını ve rivayetleri toplayıp muhtevalarına göre tasnif etmek suretiyle Hz. Âişe'ye özgü bir bakış açısı olup olmadığını ortaya çıkarmayı hedeflediğini belirtmektedir. Ayrıca mevsukiyet sorununun çok geniş isnad ve hadis çalışmalarını gerektirdiği gerekçesiyle bu araştırmanın sınırları dışında kalacağını ve rivayetleri sadece içerik ve mahiyet bakımından değerlendirmeye tabi tutacağını baştan ifade etmektedir. (s. 22)

Araştırmada başta Ahmed b. Hanbel'in Müsned'i olmak üzere temel hadis kitapları ile Taberî̀nin Câmiu'l-beyân adlı tefsiri başlıca kaynaklar olarak kullanılmıștır. Konuyla 
Vahyin Șahidi, Kur'an’ın Müfessiri Hz. Aișe. Hatice Görmez. Ankara: Otto Yayınları, 2021

ilgili 750'ye yakın rivayet içeren "Merviyyâtu ümmi'l-mü’minîn 'Âişe fi't-tefsîr"1 ve yaklaşık 5000 rivayet içeren "Mevsû'atu ümmi'l-mü'minîn 'Âişe bint Ebî Bekr" adlı iki çağdaş çalışmanın yanı sıra ayrıca dijital imkânlardan da yararlanılmıştır. (s. 23-24)

Üç bölümden oluşan çalışmanın "Hz. Aişe" başlığını taşıyan ilk bölümünde sırasıyla "Hz. Aişe'nin Şahsiyeti”, "Evlilik Yașı Etrafındaki Tartışmalar" ve "İlmi Kişiliği" ele alınmıştır. "Hz. Peygamber ile Evliliği" başlığı altında yer verilmesi daha uygun düşecek olan evlilik yaşı konusu, önemine binaen müstakil bir başlık altında incelenmiştir. Muhtemelen Hz. Âișe'nin ilmî şahsiyetine öncelik verildiği için "Evlilik Öncesi Hayatı" başlığı altında Hz. Âişe'nin çocukluk yıllarına dair arkadaşlarıyla oyun oynadığı, ilginç oyuncaklara sahip olduğu, salıncaklara bindiği vb. birçok kaynakta geçen rivayetlere değinilmemiştir. (s. 27-28)

İkinci bölümde "Tefsirde Hz. Aişe Rivayetlerinin Önemi ve Değeri" ele alınmış, "Kur'an'ın Anlaşılmasında ve Yorumlanmasında Hz. Aişe Rivayetlerinin Değeri ve Katkısı" üzerinde durulmuştur. (s. 67-89)

"Hz. Aişe'den Gelen Tefsir Rivayetleri” başlığını taşıyan üçüncü ve son bölümde ise sırasıyla tefsire dair rivayetleri, Kur'an ilimlerine dair rivayetleri, tefsirle ilişkili istidrakleri ve fetvaları, fezâil ve hasâisu'n-nebi rivayetleri, tefsir kaynaklarında farklı bağlamlarda değerlendirilen rivayetleri ve son olarak da Hz. Âişe'ye isnad edilen zorlama ve uydurma tefsir rivayetlerine yer verilmiştir.

Çalışma, Sonuç, Kaynakça ve üçüncü bölümde ele alınan rivayetlerin Arapçalarına yer verildiği Rivayetler Dizini ve Dizin kısmı ile tamamlanmaktadır.

İkinci bölümde Hz. Âişe'nin Kur'an'ın anlaşılmasında ve yorumlanmasında takip ettiği metot ve ilkeler şu on başlık altında açıklanmıştır:

1. Nassları eleştirel bir yöntemle anlama ve yorumlama çabası

2. Rivayetleri Kur'an ışığında yorumlaması

3. Bilgiyi Kur'an'dan aldığı temel ilke ve prensipler ışı̆̆ında değerlendirmesi

4. Anlama ve yorumlamada akıl-nakil dengesini gözetmesi

5. Rey ve içtihada başvurmaktan çekinmemesi

6. S S Ser'î nassların mefhum-i muhaliflerine müracaat etmesi

7. Görüşlerini Hz. Peygamber'e izafe etmekten çekinmemesi

8. Tedriciliği dikkate alması

9. Dil ve mantık kurallarını dikkate alması

10. Kolaylık prensibini dikkate alması (s. 83-89)

Kitapta Hz. Âişe'nin rivayet yöntemiyle alakalı "Başkalarından işittiği rivayetler hakkında ihtiyatlı davranır, senedini araştırır, metnini inceler sonra rivayet ederdi." denilmektedir. (s. 81) Oysa Hz. Âişe zamanında henüz isnad-sened uygulaması söz konusu olmadığından anakronizme düşmemek için "rivayetin aslını/kaynağını araştırır" denilmesi daha isabetli olacaktır.

Çalışmada Nedvî'den "Son derece sadakat, fedakârlık, samimiyet, sevgi ve muhabbet esaslarına dayanan evlilik hayatında önemli ciddi bir geçimsizlik yaşanmamış, İfk Hadisesi'nden başka dikkate değer bir hadise vuku bulmamıştır." şeklinde bir

1 Suûd b. Abdillah Fenîsan, Merviyyâtu ümmi'l-mü’minîn 'Âişe fi't-tefsîr (Riyad: Mektebetu't-Tevbe, 1992).

2 Abdulmun'im Hıfnî, Mevsû'atu ümmi'l-mü’minîn 'Âişe bint Ebī Bekr (Kahire: Mektebetu'l-Medbûlî, 2003).

https://dergipark.org.tr/tr/pub/atebe 
değerlendirme nakledilmektedir. (s. 30) Oysa ilgili ayetlerin de inmesine sebep olan ve kitabın 151-153. sayfaları arasında işlenen îlâ ve Tahyîr denilen hadise burada zikredilmeliydi.

Yazar, Hz. Âişe'nin evlilik yaşı ile ilgili görüşleri verirken ilk olarak "Arap geleneğinde kız çocuklarının yaşının akıl-baliğ olduktan sonra sayılması" başlığı altında Hristiyan din adamlarından Louis Ma'luf'un el-Müncid fi'l-luġa ve'l-'ulûm adlı lügatinde Hz. Âişe'nin 603'te doğduğunu, Hz. Muhammed ile Mekke'de nişanlandığını, Hicret'ten altı ay sonra 623'te Hz. Peygamber ile evlendiğinde yirmi yașında olduğunu, 696'da vefat ettiğini, Hicaz bölgesi Arap geleneğinde kız çocuklarının yaşının akıl-baliğ olduktan sonra sayıldığını, akıl-baliğ yaşının da on bir ile on üç yaş arası kabul edildiğini nakletmektedir. (s. 45)

Oysa adı geçen sözlüğün ikinci kısmındaki Âişe maddesi: "Âişe: (603-698). 'Mü'minlerin annesi', Ebû Bekr'in kızı ve Peygamber'in eşi (620). Ali b. Ebî Tâlib'e karşı Cemel Savaşı ile şöhret bulmuş ve o savaşta binmiş olduğu devesi öldürülmüştür. Kabri Bakî (Medine)'dedir." şeklindedir. ${ }^{3}$ Yazarın kullandığı baskıyı görme ve karşılaştırma imkânı bulamadığımı ve kız çocuklarının yaşının akıl-baliğ olduktan sonra sayıldığı bilgisini şimdilik bu veya başka bir kaynaktan teyit edemediğimi not etmeliyim.

“Ablası Esma ile aralarındaki yaş farkı" başlı̆̆ı altında Esma'nın Hicret’ten yirmi yedi yıl önce 595 tarihinde dünyaya geldiğini, Hicret esnasında 27 yaşında olduğunu belirtmektedir. (s. 46) Oysa Louis Ma'luf'un tespiti doğruysa Esma'nın yaşının da akılbaliğ olduktan sonra sayılması durumunda Hicret esnasında kırk yaşlarında olması gerekirdi.

"Iffk Hadisesinde takındığı olgun tavır” başlığı altında “Hz. Aişe'nin “Beraatimi Allah indirdi. Hamd ve șükrü ancak ona yaparım.' ifadesinde tezahür eden tavrı da ne kadar olgun olursa olsun küçük bir kız çocuğunun sergileyebileceği tavır değildir." denilmektedir. (s. 49-50) Oysa başta Buhârî olmak üzere birçok kaynağın naklettiği İfk Hadisi'nde bizzat Hz. Âişe hem de iki defa "Ve küntü câriyeten hadîsete's-sinn" (Ben o zamanlar yaşı küçük bir kız idim.) demektedir. Yazar, evlilik yaşı ile ilgili görüşüne ters düşmemek için Hz. Âișe'nin kendi ağzından yaşının küçük olduğunun çok açık bir ifadesi olan bu cümleleri "Ben o zamanlar genç bir hanım idim." (s. 142); "Ben o zamanlar henüz küçük yaşta bir kadın olduğum..." (s. 146) şeklinde tercüme etmek durumunda kalmıştır.

Zühulen bazı tekrarların görüldüğü çalışmada (s. 38, 42-43), bazı yazım hataları da göze çarpmaktadır. Söz gelimi, Heveb değil (s. 39), Hav'eb olmalı; Ebû Mansur elBağdâdî'nin eksik yazılan eserinin adı (s. 250) "Reddü'l-'uḳūli'ț-ța’işe bi żikri me'stedrekethu 'Âişe" olmalıdır.

Hz. Aișe'nin rivayetlere yönelttiği eleștirilerinin bir kısmında Hz. Peygamber'in söz ve fiiline bizzat şahit olmadığı halde onu yakından tanıyan birisi olarak "Hz. Peygamber böyle dememiştir. Dese dese şöyle demiştir." tarzındaki düzeltmeleri çok önemlidir. Bu kriterler günümüz metin tenkidi çalışmalarında da vazgeçilmez ölçüler oluşturmuş, bu konuda yeni çığırlar açmıştır. (s. 271)

Yazar bu pasaj için "Zerkeşî, el-İcâbe, s. 205" şeklinde dipnot göstermiştir. Oysa bu ifadeler Zerkeşînnin ifadeleri değil, İcabe'yi tercüme edip yayınlayan mütercime aittir. ${ }^{4}$

3 Louis Ma'luf, el-Müncid fi'l-edeb ve'l-'ulûm, (Beyrut: el-Matbaatü'l-Katolikiyye/Imprimerie Catholique, 1908), 331.

4 Bedreddin Zerkeşî, el-i̇câbe li îrâdi me'stedrekethü 'Âișe 'ale'ș-șahâhe, Hz. Aişe'nin Sahabeye Yönelttiği Eleștiriler, çev. Bünyamin Erul (Ankara: Kitâbiyât, 2000), 205. 
Vahyin Șahidi, Kur'an’ın Müfessiri Hz. Aișe. Hatice Görmez. Ankara: Otto Yayınları, 2021

Yine Nedvî'den "Cenaze namazını dönemin Medine valisi Ebû Hureyre kıldırmıştır." (s. 41) bilgisi nakledilmektedir. Oysa Vali Mervân, Ebû Hüreyre'ye geçici olarak vekalet vermiștir.

Basit istidrak kabilinden bu mülahazalardan sonra tekrar çalışmaya dönecek olursak, bir hanımefendi olarak yazar, adeta Hz. Âişe ile hemhal olmuş, onun kişiliğini çok ince bir işçilikle ortaya koyarken, konuyu tek cümle ile şöyle hülasa etmiştir:

Kısaca Hz. Aișe: Sıddık’ın kızı Sıddıka, Rasulullah’ın sevgili eşi Hümeyra, Kur'an-ı Kerim'le masumiyeti ispatlanan Müberra, mümin ve müminelere şefkat ve merhamet kanatlarını geren Müşfik Bir Ana, tüm hayatı öğrenmek ve öğretmekle geçen Eşsiz Bir Talebe ve Bilge Bir Hocadır. (s. 65)

Yine yazar Hz. Âişe'nin tefsirciliğini hadis metinlerini de vererek birçok örnekle net bir şekilde tespit etmiştir. Bu konuyu merak edenler için bir solukta okunacak hazır bir malzeme sunmakla kalmamış aynı zamanda okuyucuların ufuklarını açacak ilmî mülahazalarını da serdetmiștir. Nitekim rivayetlerin tarih boyunca karşı karşıya kaldıkları en büyük tehlikelerden birinin hadis uydurma hareketi olduğunu belirten yazarın Sonuç kısmında yaptığı şu değerlendirmeler oldukça yerindedir:

Hz. Peygamber daha hayatta iken başlayan bu hareket, ondan sonra sahabenin ileri gelenlerini de içine alarak devam etmiş ve ciddi bir boyut kazanmıştır. İnsanlar, kendi görüş ve düşüncelerini Hz. Peygamber'in yanı sıra Hz. Ali, Hz. Ömer, Abdullah b. Abbas, Hz. Aişe gibi ashabın ileri gelenlerine de isnad etmeye başlamışlardır. Neticede bu tehlikeden Hz. Aișe de nasibini almıștır. Onun Hz. Peygamber'in yakınlarından, ashabın ileri gelenlerinden ve güvenilir bir İslam şahsiyeti olması sebebiyle kendisine birçok uydurma ve zayıf haber isnad edilmiştir. Bunun sonucu olarak da Hz. Aişe'nin bize ulaşan kaynakların ekserisinde çizdiği zihnî ve ilmî profilin bazı rivayetlerine yansımadığı veya onlarla açıç̧a çeliştiği gözlemlenmektedir. (s. 322)

Tüm bunlara rağmen Hz. Aişe'nin bilhassa kadınlar aleyhine yorumlanan ayet ve hadislerin doğru anlaşılması hususundaki görüş ve eleştirilerinin önemi ve katkısı büyüktür. Zira bu konulardaki yanlışlıklar düzeltilmemiș olsaydı bunlara yenilerinin eklenmesi de kaçınılmaz olacaktı.

Sonuç olarak; Kur'an'ın anlaşılması ve yorumlanmasında Hz. Aişe'den gelen tefsir rivayetleri, anlama ve yorumlama yöntemi bakımından, Müslümanlar ve özellikle bu alanda çalışma yapan araştırmacılar için önemli bakış açıları oluşturmuştur.

Hz. Aişe, Kitap ve sünnetten aldığı İslam kültürüne kendi yorum ve düşüncelerini de katarak birçok meselede İslam toplumunu aydınlatan bir ilim ve fazilet kaynağı olmuştur. (s. 323)

Hz. Âişe'nin ilmî yönünü ve bilhassa tefsirciliğini pek çok rivayetle başarılı bir şekilde ıttılaımıza sunan değerli araştırmacı Dr. Hatice Görmez Hanımefendi'yi bu kıymetli çalışmasından dolayı gönülden tebrik ediyor, daha nice nitelikli eserlere imza atmasını diliyoruz. Asr-ı saâdetin Âişe'sini, modern asrın bir Hatice'sinden okuma hazzını yaşamak isteyen tüm okurlara bu kitabı hararetle tavsiye ederken, OTTO Yayınları'na da bu güzel kitaptan dolayı teșekkürlerimizi sunuyoruz. 
Bünyamin Erul

\section{Kaynakça}

Fenîsan, Suûd b. Abdillah. Merviyyâtu ümmi'l-mü’minîn 'Âişe fi't-tefsîr (Riyad: Mektebetu'tTevbe, 1992).

Hıfnî, Abdulmun'im. Mevsû́atu ümmi'l-mü’minîn 'Âişe bint Ebî Bekr (Kahire: Mektebetu'lMedbûlî, 2003).

Ma'luf, Louis. el-Müncid fi'l-edeb ve'l- 'ulûm. Beyrut: el-Matbaatü'l-Katolikiyye/Imprimerie Catholique, 1908.

Zerkeșî, Bedreddin. el-İcâbe li îrâdi me'stedrekethü 'Âișe 'ale'ș-șahâbe, Hz. Aişe'nin Sahabeye Yönelttiği Eleștiriler. çev. Bünyamin Erul. Ankara: Kitâbiyât, 2000. 